\title{
3 次元表示のプロセス
}

\author{
川井孝之 : 海洋情報課
}

3 Dimensional Processing.

Takayuki Kawai : Oceanographic Data and Information Div.

\section{1. はじめに}

コンピュータグラフィックス（以下略 CG）は，大きな可能性を秘めた新しいメディアとしてさまざまな 分野に浸透しつつある。そして, これらの背景には, CGにより出力された図の持つ情報量の多さに加え, ハード，ソフトウェアー技術の進歩によるプログラミングの単純化が掲げられるであろう。 特に後者においては, 乙て数年の目覚しい進歩により, 以前一部の専問家に任せられていた複雑なプログラ ミングを，パッケージ化されたサブルーチンを使用することにより，図形処理に関する知識をまったく持た ないユーザーが代行するととを可能とした。

現在, 水路部で使用されているグラフィックパッケージ, “RASPAK”*1, 及び “GEOPAK”*2 は, 乙の 様なユーザー指向型のグラフィックパッケージであり, FORTRAN (V) モード環境下で動作する各々の図 形処理サブルーチンが用意されている。乙れらのパッケージを使用するととにより，豊富なカラー表示と共 に, 従来の 2 次元（以下略 2 D）を表現に加え, 3 次元（以下略 3 D）による新しい表現方法が可能となった。

ここでは, これらのグラフィックパッケージの特徴である 3 D 表示を例に取り, “RASPAK”, “GEOPAK” の使用例を示すと共に，そのブラックボックスであるサブルーチンのアルゴリズムを，基本的な図形処理論 と対応しながら紹介することにしたい, このととにより, これらサブルーチンの機能を理解し, 又ソフトウ ェアー開発の参考となれば幸いである。

\section{3 次元表示のプロセス}

$3 \mathrm{D}$ 表示は, 我々が日常目にする $3 \mathrm{D}$ 空間の表現が可能なため, よりリアルな表示が期待出来る。

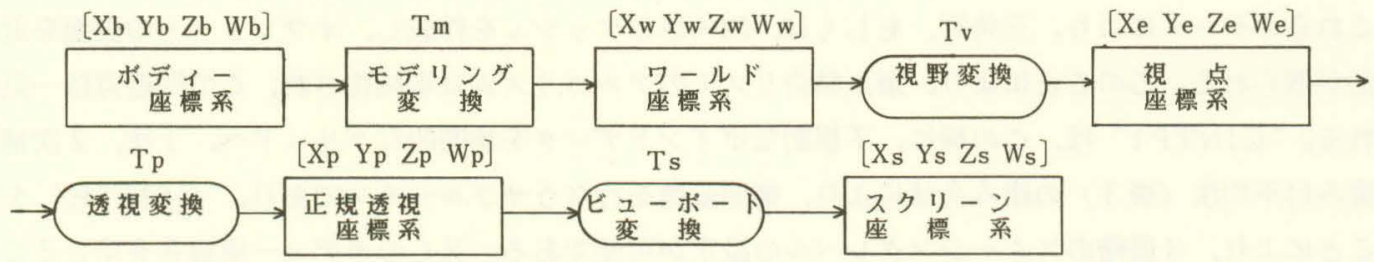

第1図 3 D 表示のプロセス

\footnotetext{
* 1 "RASPAK"

基本的なラスターイメージを取り扱うパッケージであり, ベクター〜ラスター変換，エリアシェイティング, ポイントプロット, カラー指定, テキストプロット等を行う。

* 2 "GEOPAK"

“R ASPAK”下で使用するマッピングパッケージであり, 等高線図, 透視図等の作成を行う。
} 
このことにより，CG は CAD 等に見られる様に，その適用範囲は，加速度的な拡がりを見せたといえよう。 それでは, $3 \mathrm{D}$ 表示はどの様なアルゴリズムによって $2 \mathrm{D}$ 空間へ投影されるのであろうか。第 1 図を参照し ていただきたい……との様に，3 D 表示は，2D 表示とは異なるプロセスを遂て $2 \mathrm{D}$ 空間であるディスプ レー,プロッター上へ投影される。乙れは, “GTRANS”により行なわれるが，乙てでは，それより下の レベルによるアルコリズムを，3D 表示における座標系，及びその座標変換理論を示しながら紹介するとと としたい。

\section{2-1 モデリング}

$2 \mathrm{D}$ 表示においては, グローバルな座標系に直接図形を定義するのが普通である。しかし，3 D 表示で取 り扱う $3 \mathrm{D}$ オブジェクトを対象とした場合, 前記の様な座標系に, 3D オブジェクトを直接定義するととは, 大変困難な作業となる。そこで, $3 \mathrm{D}$ 表示においては, $2 \mathrm{D}$ 表示のマスター座標系に相等するローカルな (オ

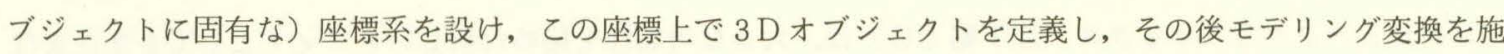
して $3 \mathrm{D}$ シーンを定義するのが一般的な手順となる。それでは, このローカルな座標系であるボディー座標 系によって, $3 \mathrm{D}$ オブジェクトはどの様に定義 (モデリング) されるのであろうか。

このモデリング技術は CG 分野よりはむしろ数値制御 (Numerical Control, 略して NC) 工作機分野にお いてつちかわれ，形状処理工学に見られる様に数々の方法が考え出されている。

球の様な定形的なオブジェクトの場合, 簡単な数式により, その表面上に位置する点は無限個求めること が出来る。そこで, 乙れらの点群データを, 後に紹介する座標変換を用い, プロッタ上に作画したとしよう。 我々は，乙の出力された図を見た場合，そこに“球”を見ることが出来る。だが，乙れは球をモデリングし たことにはならない。なぜならば, 我々はその図を見て, 経験的に“球”として見ているのに対し, コンピ ュータにとっては, 球の表面上に分布した, 単なる点群として見ているからである。つまり, てれらのデー 夕は, 点の位置情報 $\left(\mathrm{P}_{\mathrm{x}}, \mathrm{P}_{\mathrm{y}}, \mathrm{P}_{z}\right)$ のみであり, 体積を有する $3 \mathrm{D}$ オブジェクトを, 点だけでは定義出来 ないからである。そてで, 3Dオブジェクトをモデリングする場合, てれらの点群データを, 何らかの方法 により結合することで面を作り，乙れらの面の集合体として $3 \mathrm{D}$ オブジェクトを定義するのが，一般的な方 法である。つまり，3Dオブジェクトをモデリングするためには，その大きさ（座標値） $70 \mathrm{i}$, 形状（頂点 結合リスト) が新しい情報として必要となる。

我々が, 取り扱うデータは, 水深データ等に見られる様に, ランダムなポイントデータである場合が多く, 又そのデータの表わすオブジェクトの形状（海底地形）あ不定形な場合が殆んどである。しかし，ての様な データを用い, 前述した様な頂点結合リストを作るのはかなり複雑なアルゴリズムを用する。従って, 通常 は, これらのデータにより, 三角形, あしくは, 四角形のメッシュを作成し, オブジェクトの表面を近似す る方法が取られる。このことにより, 頂点結合リストのアルコリズムは単純化され, この問題点は一気に解 消される。“GINTP1”は，乙の様に，不規則なポイントデータを規則的なグリッドへ，1 次，2 次補間， 及び重み付平均法（※3）の組み合せにより, 補間変換を行なうサブルーチンであり, “GSMTH”を使用 するととにより，3段階のスムージングレベルの設定が可能である。又とのボディー座標系を用いるととに より, 3D オブジェクトの体積を計算することが可能である。

※3) 重み付平均法

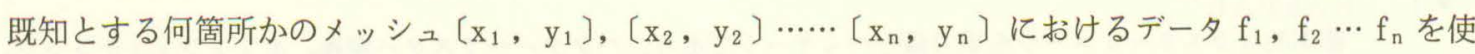
用し, 未知であるメッシュ〔x, y〕におけるデー夕 $\mathrm{f}$ を, 滑らかな曲面で補間する方法であり, (1) 式が用 
いられている。

$$
f(x, y)=\frac{\sum_{i=1}^{n}\left(f_{i} / \sqrt{\left(x_{i}-x^{2}\right)+\left(y_{i}-y\right)^{2}}\right.}{\sum_{i=1}^{n}\left(1 / \sqrt{\left(x_{i}-x^{2}\right)+\left(y_{i}-y\right)^{2}}\right.}
$$

ただし, データ $\mathrm{f}_{\mathrm{i}}$ が与えられたメッシェに拈いては，(1) 式によらず $\mathrm{f}_{\mathrm{i}}$ とする。式 (1) の分子は, 点〔 $\mathrm{x}$, y ] での高さを求めるとき, 既知点に近い点であるほど大きな重みを付ける様にしたあのであり, 分母は, そのデータに対する重みの総和が 1 となる様に, 正規化するための項である。この式が定義域内で連続であ り, 滑らかな曲面を創成することは容易に想像出来よう。しかし, ての式の大きな欠点として既知点におけ る曲面の接平面がすべて水平になってしまうことが掲げられる。つまり

$$
\begin{aligned}
& \frac{\partial}{\partial x} f(x, y) \mid x=x_{i}, y=y_{i} \\
= & \frac{\partial}{\partial y} f(x, y) \mid x=x_{i}, y=y_{i}=0
\end{aligned}
$$

となり，乙のことは既知点では，すべてが滑らかな頂上や，滑らかな凹みの底であるか，あるいは坂の途中 の水平な場所（階段における舞り場の様な所）になってしまうことを意味する。このととにより, 起伏に富 んだ海底地形などの場合, 丸められてしまい, 実際のイメージとは異なる図形が表示されてしまう可能性が あることに留意されたい。

\section{$2-2$ モデリング変換}

$3 \mathrm{D}$ オブジェクトの形状を定義したボディー座標系から 3 D ワールド座標系への変換は, モデリング変換 と呼ばれる変換により行なわれる。乙れは, オブジェクトの動きや向きに対しての変換であり, 回転, 平行 移動, 及びスケーリングにより, 以下に示すアフェイン変換により定義される。こてで，3D ワールド座標 系とは, ボディー座標系に対して, グローバルな座標系であり, ユーザーの使用するワークエリアの様なむ のである。

平行移動：T

$$
\mathbf{T}=\left(\begin{array}{cccc}
1 & 0 & 0 & 0 \\
0 & 1 & 0 & 0 \\
0 & 0 & 1 & 0 \\
\mathrm{~T}_{\mathrm{x}} & \mathrm{T}_{\mathrm{y}} & \mathrm{T}_{\mathrm{z}} & 1
\end{array}\right) \text { スケール変換: } \mathbf{S} \quad \mathbf{S}=\left(\begin{array}{cccc}
\mathrm{S}_{\mathrm{x}} & 0 & 0 & 0 \\
0 & \mathrm{~S}_{\mathrm{y}} & 0 & 0 \\
0 & 0 & \mathrm{~S}_{z} & 0 \\
0 & 0 & 0 & 1
\end{array}\right)
$$

$\mathrm{x}, \mathrm{y}, \mathrm{z}$ 各軸に対する変換: $\mathrm{R}_{\mathrm{x}}, \mathrm{R}_{\mathrm{y}}, \mathrm{R}_{\mathrm{z}}$

$$
\mathbf{R}_{\mathrm{x}}=\left(\begin{array}{cccc}
1 & 0 & 0 & 0 \\
0 & \cos \theta_{\mathrm{x}} & \sin \theta_{\mathrm{x}} & 0 \\
0 & -\sin \theta_{\mathrm{x}} & \cos \theta_{\mathrm{x}} & 0 \\
0 & 0 & 0 & 1
\end{array}\right), \mathbf{R}_{\mathrm{y}}=\left(\begin{array}{cccc}
\cos \theta_{\mathrm{y}} & 0 & -\sin \theta_{\mathrm{y}} & 0 \\
0 & 1 & 0 & 0 \\
\sin \theta_{\mathrm{y}} & 0 & \cos \theta_{\mathrm{y}} & 0 \\
0 & 0 & 0 & 1
\end{array}\right), \mathbf{R}_{\mathrm{z}}=\left(\begin{array}{cccc}
\cos \theta_{z} & \sin \theta_{z} & 0 & 0 \\
-\sin \theta_{z} & \cos \theta_{z} & 0 & 0 \\
0 & 0 & 1 & 0 \\
0 & 0 & 0 & 1
\end{array}\right)
$$


$3 \mathrm{D}$ ワールド座標系を〔 $\mathrm{x}_{\mathrm{w}}, \mathrm{y}_{\mathrm{w}}, \mathrm{z}_{\mathrm{w}}$,

1], ボディー座標系を $\left[\mathrm{x}_{\mathrm{b}}, \mathrm{y}_{\mathrm{b}}, \mathrm{z}_{\mathrm{b}}, 1\right]$

とすると，

$$
\begin{aligned}
{\left[\mathrm{x}_{\mathrm{w}}, \mathrm{y}_{\mathrm{w}}, \mathrm{z}_{\mathrm{w}}, 1\right]=} \\
\underset{\left.\mathrm{x}_{\mathrm{b}}, \mathrm{y}_{\mathrm{b}}, \mathrm{z}_{\mathrm{b}}, 1\right] \cdot 1}{\mathrm{~S} \cdot \mathrm{R}_{\mathrm{x}} \cdot \mathrm{R}_{\mathrm{y}} \cdot \mathrm{R}_{\mathrm{z}} \cdot \mathrm{T}} \\
\underset{\mathrm{T}}{\mathrm{T}_{\mathrm{m}}}
\end{aligned}
$$

\section{$2-3$ 視野変換}

3D ワールド座標系で定義した 3D シーンを見るための変換であり, 前述

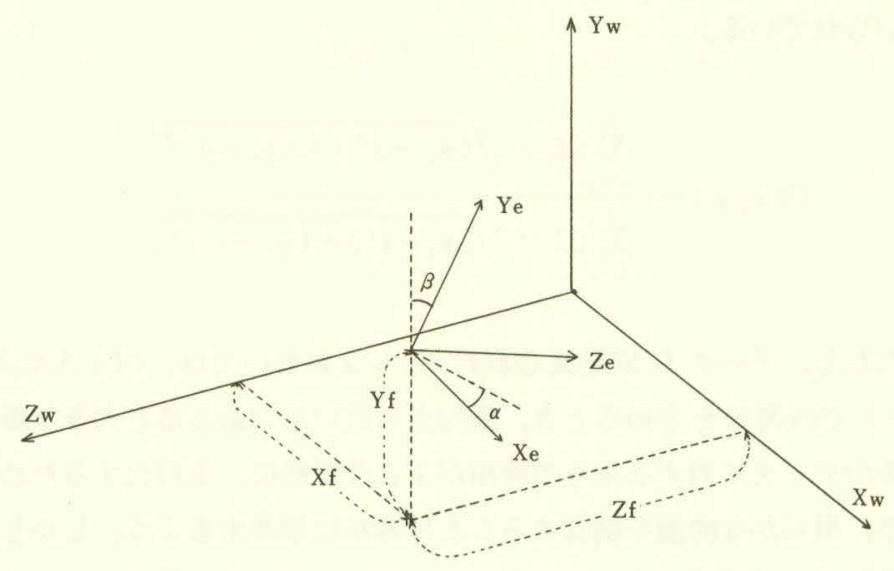

第 2 网

した各座標系と異なり, 視点を原点と

し，視線を Z 軸の正方向に取った左手系の座標系である。3D ワールド座標系との関係を第 2 図に示す。 $x_{e}$ 軸は $\mathrm{x}_{\mathrm{w}}-\mathrm{z}_{\mathrm{w}}$ 平面に平行にとるため, 回転は 2 回で斎ませ, 最後に $Z$ 軸の向きを反対にすることにより, 右手 系 $\rightarrow$ 左手系へと変換する。

$\mathrm{x}_{\mathrm{w}}, \mathrm{y}_{\mathrm{w}}, \mathrm{z}_{\mathrm{w}}$ 軸方向にそれぞれ $\mathrm{x}_{\mathrm{f}}, \mathrm{y}_{\mathrm{f}}, \mathrm{z}_{\mathrm{f}}$ だけの平行移動： $T_{1}$

$$
\mathbf{T}_{1}=\left(\begin{array}{cccc}
1 & 0 & 0 & 0 \\
0 & 1 & 0 & 0 \\
0 & 0 & 1 & 1 \\
-\mathrm{x}_{\mathrm{f}} & -\mathrm{y}_{\mathrm{f}} & -\mathrm{z}_{\mathrm{f}} & 1
\end{array}\right)
$$

さらに視点 $\mathrm{x}_{\mathrm{e}}$ 軸の回りにー $\beta$ だけ回転： $T_{3}$

$$
\mathbf{T}_{3}=\left[\begin{array}{cccc}
1 & 0 & 0 & 0 \\
0 & \cos \beta & \sin \beta & 0 \\
0 & -\sin \beta & \cos \beta & 0 \\
0 & 0 & 0 & 1
\end{array}\right]
$$

視点の回りにー $\propto$ だけ回転： $T_{2}$

$$
\mathrm{T}_{2}=\left[\begin{array}{cccc}
\cos \alpha & 0 & -\sin \alpha & 0 \\
0 & 1 & 0 & 0 \\
\sin \alpha & 0 & \cos \alpha & 0 \\
0 & 0 & 0 & 1
\end{array}\right]
$$

右手系 $\rightarrow$ 左手系への変換 : $T_{h}$

$$
\mathbf{T}_{\mathrm{h}}=\left(\begin{array}{cccc}
1 & 0 & 0 & 0 \\
0 & 1 & 0 & 0 \\
0 & 0 & -1 & 0 \\
0 & 0 & 0 & 1
\end{array}\right)
$$

視点座標系を $\left[\mathrm{x}_{\mathrm{e}}, \mathrm{y}_{\mathrm{e}}, \mathrm{z}_{\mathrm{e}}, 1\right]$ とす

ると,

$$
\left[\mathrm{x}_{\mathrm{e}}, \mathrm{y}_{\mathrm{e}}, \mathrm{z}_{\mathrm{e}}, 1\right]=\left[\mathrm{x}_{\mathrm{w}}, \mathrm{y}_{\mathrm{w}}, \mathrm{z}_{\mathrm{w}}, 1\right] \cdot \mathrm{T}_{1} \cdot \mathrm{T}_{2} \cdot \mathrm{T}_{3} \cdot \mathrm{T}_{\mathrm{h}} \cdots \cdots \text { 視野変換 }
$$

これらの機能は, サブルーチン“GVUANG”及び “GEYE”に相当する。

\section{$2-4$ 透視変換}

視点を中心として記述されている視点座標系を $2 \mathrm{D}$ 空間である表示装置へ投影するととを透視投影といい， この変換を行なうのが透視変換である。これらの変換式は, 第 3 図からわかる様に、表示装置上の座標を, $\left[\mathrm{x}_{\mathrm{p}}, \mathrm{y}_{\mathrm{p}}, \mathrm{z}_{\mathrm{p}}\right\rfloor$ とすると次式となる。 


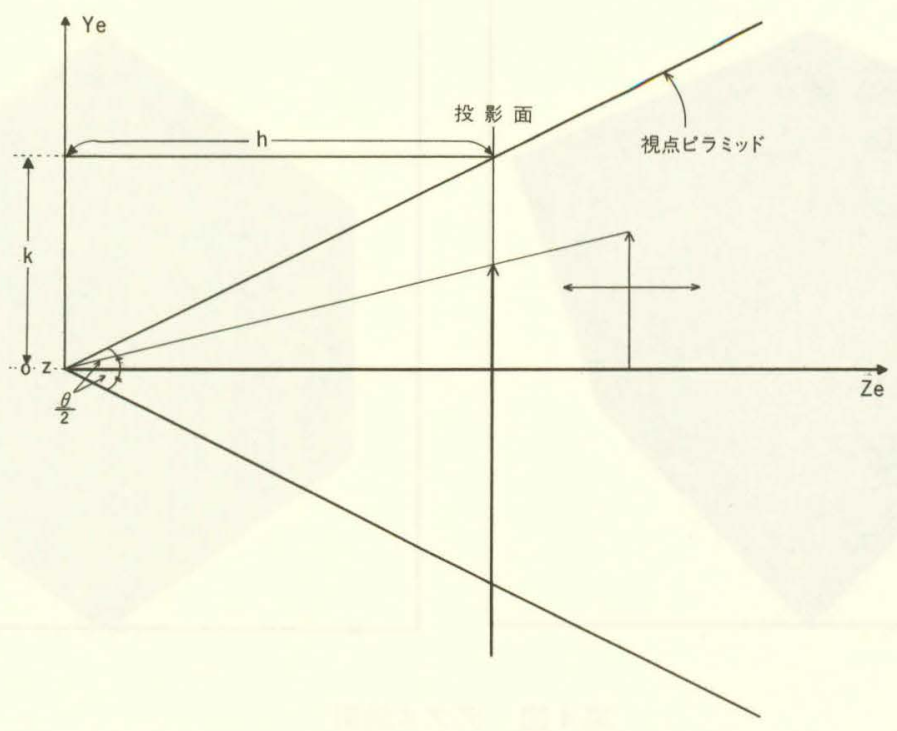

第 3 図

$$
\left.\begin{array}{l}
x_{p}=\frac{h}{k} \cdot \frac{x_{e}}{z_{e}} \\
y_{p}=\frac{h}{k} \cdot \frac{y_{e}}{z_{e}} \\
z_{p}=1-\frac{h}{z_{e}}
\end{array}\right\}
$$

ここで, (2) 式, 及び第 3 図より, 透視図における視角を $\theta$ とすると,

$$
\tan (\theta / 2)=\mathrm{k} / \mathrm{h} \text { となる。 }
$$

そこで, (2) 式の第 2 式を, $z_{\mathrm{e}}$ に関して微分すると,

$$
\begin{aligned}
\frac{d y_{p}}{d z_{e}} & =-\frac{h}{k} \cdot \frac{y_{e}}{z_{e}{ }^{2}} \\
& =-\frac{k}{h} \cdot \frac{y_{p}{ }^{2}}{y_{e}}=-\tan \frac{\theta}{2} \cdot \frac{y_{p}{ }^{2}}{y_{e}}
\end{aligned}
$$

となる。乙れは, $\mathrm{z}_{\mathrm{e}}$ に対する $\mathrm{y}_{\mathrm{p}}\left(\mathrm{x}_{\mathrm{p}}\right.$ についても同様に) の変化を示す。つまり投影図の奥行きの強調度を 表わしている。乙の機能はサブルーチン “GDIST”により行うことが出来る。しかし，（3）式より，k／h の值を $1 / 2$ 倍にすると投影図の大きさは 2 倍になってしまい, 乙のため, 投影図の大きさを一定に保つた めには, 視点の位置を, 2 倍だけ視点から遠ざけなければならない。これは, 3 D ワールド座標系における 視点の位置 $\mathrm{z}_{\mathrm{e}}$ 值を変化させるのが簡単な方法である。

第 4 図に, “GDIST”によるデプス効果を示す。（a ) 図はオブジェクトに目を近づけた場合に見られる図 （広角レンズにより得られる像）に相当し，（b）図はオブジェクトから遠ざかって見た場合（望遠レンズに より得られる像）に相当する。 

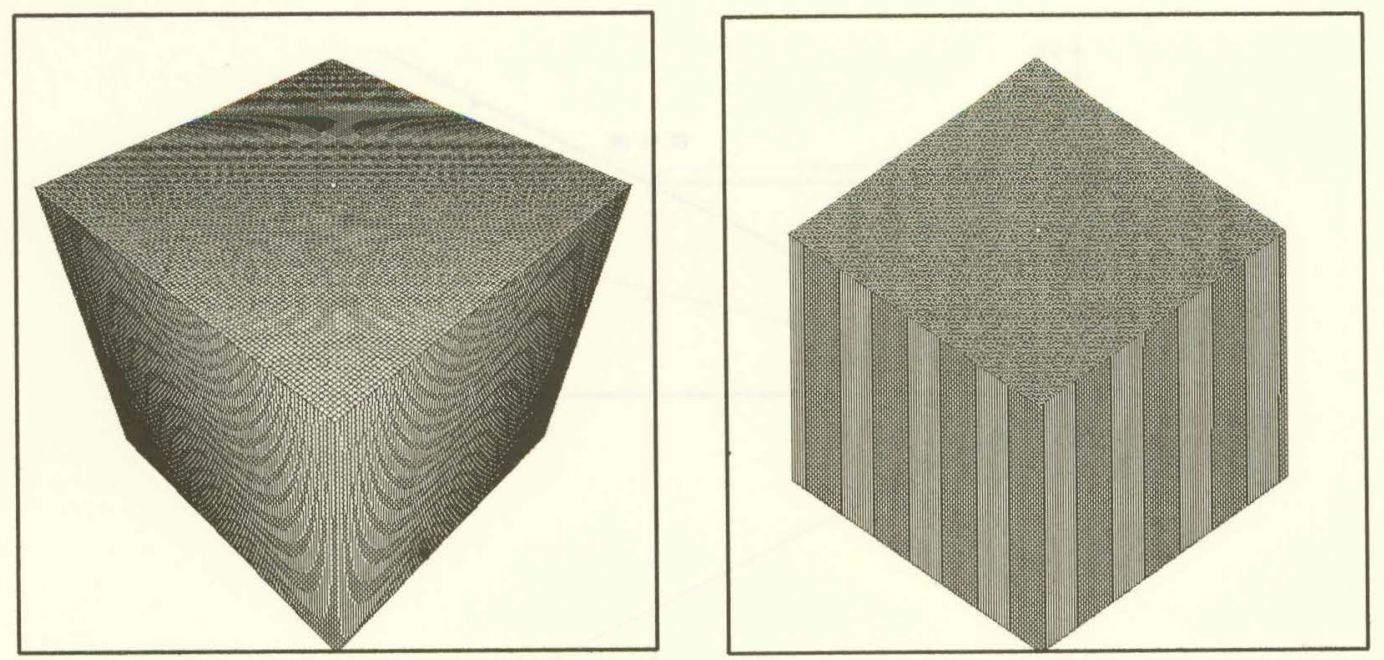

第4図 デプス効果

3. “RASPAK” におけるカラーモデル

"RASPAK" では, 3 つの 2 析の数字によって構成さ れるカラーコードにより, 豊富なカラー表示が出来る。 3 つの 2 析の数は各々 0 〜 16 のレンジを有し, 対応する 基本 3 原色のシェイドやパターンの違いにより, $17 \times 17$ $\times 17=4,913$ 色の相合せが可能である。これは, ハード 的に見ると，第 5 図に示す様な干渉縞が少なくなる様に 工夫された $4 \times 4=16$ ピクセル（画素）によるビットプ レーンを設け, カラープロッターにより, シアン, マゼ ンタ, イエローの各インクを吹き付けるととにより, 中 間色を出している。乙れらのカラーテーブルは, サブル ーチン “GCOLOR” により設定され, 又サブルーチン “GCMODE” の使用により，4 種類のカラーモデルの 選択が可能である。

\section{3-1 RGB カラーモデル}

赤, 緑, 青よりなるカラーモデルは, 直交座標系を用 いて表わすと, 第 6 図のようになる。RGBでは, 各原色 の個々が寄与して一諸に加えられた結果を作るために, 加法原色と呼ばれる。

\section{3-2 CMYカラーモデル}

赤, 緑, 青の補色であるシアン, マゼンダ, イエロー は, 白色光からあるカラーを減ずるととにより, 減法原 色と呼ばれる。乙れは, 面がシアン色のインクで塗られ

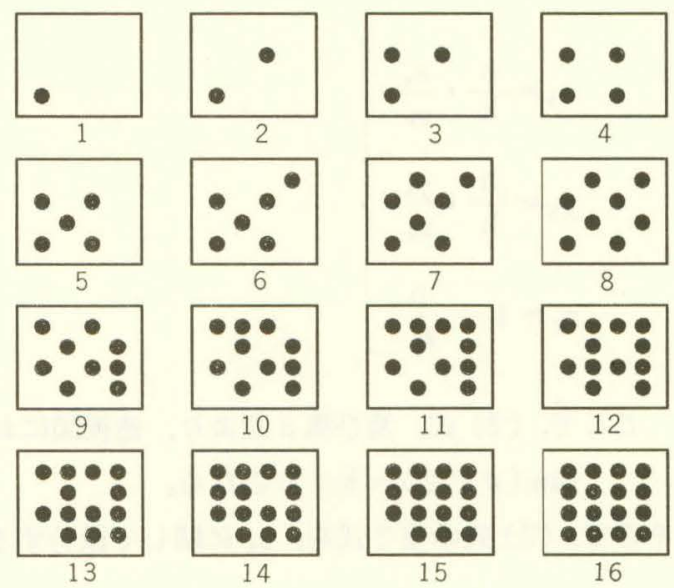

第 5 図

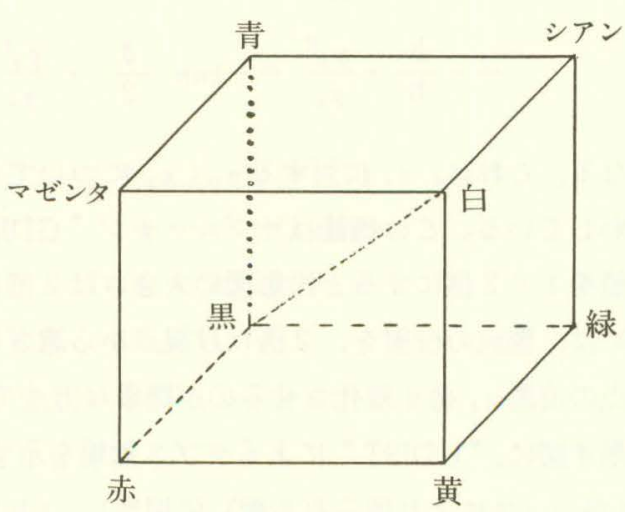

第6 図 RGB カラー立方体 
ている場合, その面からは, 赤, 緑, 青の白色光より, 補色である赤を減じ, 従って加法原色の観点からは, 青 プラス緑となる。 RGB と CMY との関係は次式によって 表わされる。

$$
\left(\begin{array}{c}
C \\
M \\
Y
\end{array}\right]=\left(\begin{array}{l}
1 \\
1 \\
1
\end{array}\right)-\left(\begin{array}{l}
R \\
G \\
B
\end{array}\right)
$$

\section{3ー3 HLS カラーモデル}

Tektronix で使用された Ostwald [OSTW 31〕カラー システムに基づく HLSは, 第 7 図で示される様な双 6 角 錐部分空間によって表わされる。色相は, 青を $0^{\circ}$ とする 垂直軸の回りの角度, 明るさは垂直軸, 又飽和は中心軸 から双 6 角錐の側面までの割合で表わされる。

HLS カラーモデルでは, 反対側 $\left(180^{\circ}\right)$ の色相では, 補色を表わし, 又中心軸上では, グレイスケールとなる。 RGB, CMY モデルは, ハードウェアー向きであるのに 対し, HLS モデルは直感に訴えるととに基づいて, ユ

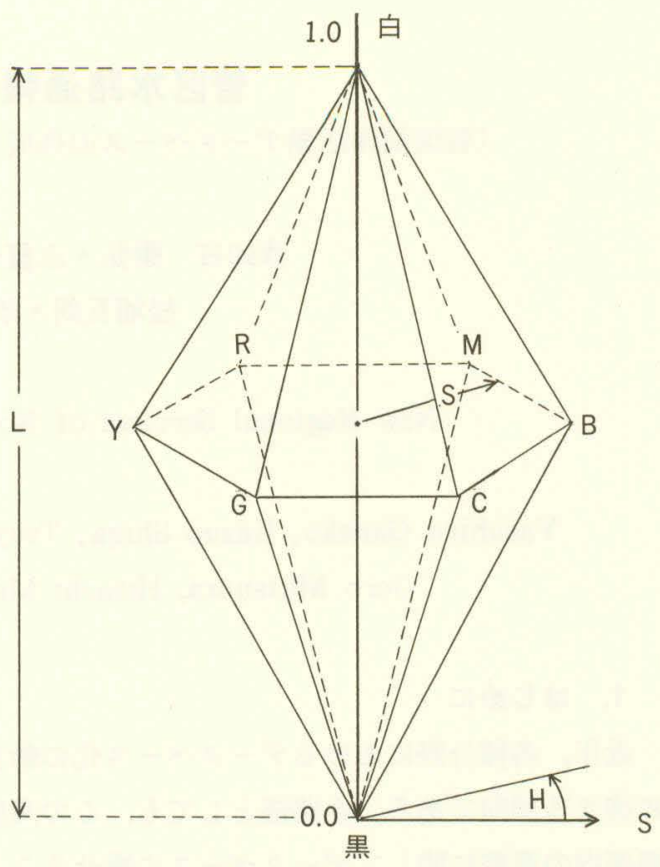

第 7 図 双六角錐 HLS カラーモデル ーザー向きといえる。

\section{4. むすび}

ここで紹介したサブルーチンは, “RASPAK”及び, “GEOPAK”のほんの一部にすぎない。紙面の都 合上各サブルーチンの使用方法を紹介することが出来なくて残念である。興味のある方は, 海洋情報課にマ ニュアルがあるので参照されたい。これら豊富な図形処理サブルーチンを使用し, 海底地形鳥暇図にとらわ れない, 新しい表現を期待する次第である。

\section{報 告 者 紹 介}

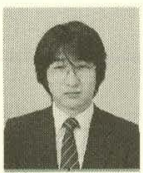

\section{Takayuki Kawai}

川井孝之 昭和 62 年 3 月現在, 本庁水路部海洋情報課海洋情報官付 